\title{
Um movimento (auto)biografado
}

An Autobiographical Social Movement

\author{
Carolina Cechella Philippi' (iD) 0000-0001-6121-254X \\ 'Universidade Estadual de Campinas, Faculdade de Educação, Campinas, SP, Brasil. \\ 13083-865-posfe@unicamp.br
}

DAVIS, Angela.
Uma autobiografia.

Trad. de Hecci Regina Candiani. São Paulo: Boitempo, 2019.

A autobiografia de Angela Davis foi originalmente publicada quando a autora tinha 28 anos, em 1974, mas somente em 2019 recebeu sua publicação brasileira pela Editora Boitempo, contando com prefácio Raquel Barreto e a orelha de Anielle Franco. Ao ser questionada sobre seu conteúdo durante sua estada no Brasil, Angela Davis descreve como uma "autobiografia de um movimento" (Mídia NINJA, 2019, 8'36"). Essa definição é evocada por entender o gesto de biografarse como forma de narrar lutas coletivas às quais se articulou ao longo de sua trajetória pessoal e acadêmica. A autora, filósofa e professora emérita da Universidade da Califórnia, integrou o Partido Comunista dos Estados Unidos e foi próxima aos Panteras Negras na década de 1970. Sua visibilidade ganhou alcance mundial pela mobilização que seu encarceramento gerou pela via da campanha "Libertem Angela Davis" (Angela DAVIS, 2019, p. 267-320). Para além disso, sua trajetória pessoal e acadêmica ganhou notoriedade pela atuação no combate ao racismo, na luta pela interseccionalidade e na resistência às políticas de encarceramento (Isabela ALEIXO, 2019).

Por esse motivo, a publicação é especialmente voltada considerando sua trajetória profissional, pessoal e de engajamento. A autora faz a opção de organizá-la fora da ordem linear do tempo. Sendo assim, os capítulos - "Redes", "Rochas", "Águas", "Chamas", "Muros" e "Pontes" - versam sobre momentos distintos de sua vida que não necessariamente são dispostos em maneira cronológica. O primeiro deles se dedica a uma detalhada narração do período passado no cárcere ${ }^{\prime}$ em Nova York até sua extradição para a Califórnia. O título escolhido é duplamente conveniente pelos dois possíveis sentidos para o termo "rede". O primeiro faz alusão a um gesto de aprisionamento, que conversa diretamente com sua experiência no cárcere e encontra respaldo na citação apresentada em seu início - "a rede será rasgada pelo chifre de um bezerro saltitante" (DAVIS, 2019, p. 23). Há, porém, o segundo significado, que faz alusão a uma rede de apoio que serve não para aprisionar, mas para sustentar. Esse sentido ganha força quando são descritas as experiências de engajamento pessoal e coletivo no cárcere. Chama atenção o uso reiterado do termo "irmãs" (DAVIS, 2019 , p. $43 ; 48 ; 62 ; 64 ; 68$; 69) para se referir às demais encarceradas e a descrição constante dos levantes sucessivos pela sua libertação que tomaram corpo dentro e fora do espaço prisional.

\footnotetext{
${ }^{1}$ Na década de 1970, Angela Davis passou a militar na luta por reformas no sistema prisional. Na ocasião, estudava o caso de três jovens negros, acusados de matarem um policial. Porém, um dos acusados sublevou-se no momento do julgamento. Nesse interim, Angela Davis foi acusada de participar do levante. Foi o bastante para que ela fosse considerada uma potencial criminosa, condenada e confinada em 1971.
} 
O capítulo seguinte - "Rochas" - dá lugar às descrições de infância e adolescência. O termo faz uma alusão visual ao espaço para o qual sua família se mudou em 1948², na Rua Central de Birmingham. A colina que passaram a ocupar foi palco de algumas das primeiras experiências de discriminação racial que ocuparam suas reminiscências. Elas reverberaram em outros espaços de socialização de sua infância e adolescência, sobretudo no universo escolar e na pouca representatividade epistêmica presente no currículo. Essa impressão se estreitou ao final de sua vida escolar, sobretudo:

na época em que entrei no ensino médio, o movimento pelos direitos civis estava começando a despertar parte da população negra no Alabama de seu sono profundo, mas aflito. No entanto, a julgar pela inatividade da Parker High School, nunca saberíamos que Rosa Parks tinha se recusado a mudar para os fundos do ônibus [...] em 1955 (DAVIS, 2019, p. 110).

É em seu percurso acadêmico e em seu engajamento político que se centra "Águas". Nele, discorre a respeito do percurso nas universidades que ocupou dentro e fora do país e narra as primeiras incursões nas leituras de filosofia. Paralelamente, narra também as sensações causadas pela distância da terra natal e dos movimentos de engajamento do povo negro que ali se alinhavavam. Foi essa sensação, acalentada pelo episódio da explosão da igreja de Birmingham ${ }^{3}$, que fez crescer os já existentes anseios de retorno aos Estados Unidos. Após isso, concluiu que a capacidade de realização de algo dependia intrinsecamente de sua capacidade de envolvimento concreto com as lutas travadas na realidade. É quando retorna aos Estados Unidos ou, parafraseando a epígrafe desse mesmo capítulo, volta "à paisagem do gênesis; de estrondos, choques e águas" (DAVIS, 2019, p. 123).

"Chamas" é o capítulo mais extenso do livro. Não por acaso, é através dessa imagem flamejante que a autora reporta seus anos de militância, pois descreve a comum confusão dos militantes homens entre sua atividade política e a afirmação de sua masculinidade. Em suas palavras:

Eu me familiarizei muito cedo com a presença generalizada de uma lastimável síndrome entre alguns ativistas negros do sexo masculino: a de confundir a sua atividade política com a afirmação de sua masculinidade. Eles viam [...] a condição de homem negro como algo separado da condição de mulher negra (DAVIS, 2019, p. 163).

Tal padrão de comportamento, para Davis, dificulta a elaboração de pautas reivindicatórias e a organização no interior dos movimentos já que, por definição, relegam às mulheres atividades que não as aproximam da liderança, afastando-as dos espaços públicos.

Foi também por considerar "a revolução [...] a coisa mais séria na vida de uma pessoa revolucionária" (DAVIS, 2019, p. 164) que, em meados de 1968, percebeu a necessidade de encontrar um grupo. O ingresso aos Panteras Negras é então mapeado sem, contudo, obliterar suas dissidências internas, bem como as discordâncias dentro da população negra a respeito da forma pela qual demandavam se engajar. Tais conflitos são abordados na autobiografia, o que permite nuançar a memória de tais movimentos sociais.

O período passado entre os "Muros" da prisão da Califórnia é tratado no capítulo homônimo. Nele, chama atenção a narrativa a respeito da insensatez e do vazio hipnótico da rotina no cárcere e das reincidentes tentativas de Angela - e também pelas pessoas que encamparam sua defesa - em prol de sua soltura. Esses "muros" são redimensionados também no capítulo "Pontes" já que "virados de lado, muros são pontes"5 (DAVIS, 2019, p. 337). É nesse capítulo final que Angela Davis se demora sobre seu julgamento e sua posterior absolvição. Porém, para além disso, ganha destaque a sua militância posterior e ininterrupta a fim de que demais presos por motivos políticos fossem também inocentados. Destaca a responsabilidade que lhe recaiu após sua absolvição já que a sua capacidade de "manter o movimento vivo" (DAVIS, 2019, p. 381) poderia significar uma das poucas esperanças para aqueles que permaneciam atrás dos muros. Narra então que "nos encontros de massa, frequentados predominantemente por pessoas negras, explicava que minha presença diante delas significava que [...] o poder imenso de pessoas unidas e organizadas para transformar sua vontade em realidade" (DAVIS, 2019, p. 381-382).

A autobiografia de Angela Davis tem a relevância calcada na apresentação de momentos e episódios da trajetória de uma mulher negra na luta pelos direitos civis nos Estados Unidos e também nos relatos de seu cotidiano no cárcere. Trata-se, portanto, de uma narrativa central para o entendimento sobre seu engajamento político e de uma posterior trajetória intelectual. Para além disso, a escrita feita por mulheres negras, em sentido próximo ao proposto por Conceição Evaristo',

\footnotetext{
${ }^{2}$ O capítulo é assim epigrafado: “Tenho uma casa em cima daquela rocha, você não está vendo?” (DAVIS, 2019, p. 87). ${ }^{3}$ Referência ao atentado ocorrido em um bairro negro de Birmingham em 1963. Na ocasião, quatro jovens negras foram mortas.

${ }^{4}$ Trecho do poema "Céu Vivo", de Frederico Garcia Lorca.

${ }^{5}$ Citação empregada pela autora em epígrafe do capítulo "Pontes".

" É importante ressaltar que, na entrevista concedida à TV PUC Rio, Conceição Evaristo abordou seu próprio processo de escrita e seu tangenciamento com sua subjetividade. A aproximação dessa elaboração com a autobiografia de Angela Davis foi feita pela autora da resenha.
} 
traz consigo uma potência de voz coletiva das mulheres negras, sendo que também essa condição interfere na narrativa que é feita de si. Trata-se, portanto, de uma escolha que se relaciona como a própria subjetividade (TV PUC-Rio, 2017, 9'53"). É nessa potência que pulsa grande parte da representatividade que Uma autobiografia traz, sendo ela central para estudos sobre gênero, raça e sua interseccionalidade. Tal centralidade, porém, não oblitera seu caráter de documento e descrição histórica (DAVIS, 2019, p. 15-18), pois se trata de uma perspectiva a respeito de um movimento que se desdobrou em diferentes espaços. Sendo assim, a centralidade da obra não a torna totalizante. Nesse sentido, a narrativa encampada pela própria Angela Davis é contundente: embora o livro trate de uma trajetória pessoal e de seu conteúdo político, ela não o esgota. É um convite a uma perspectiva interseccional para entendimento dos movimentos sociais e de uma provocação para pensar o papel e a representatividade da militância e do engajamento político na atividade acadêmica.

\section{Referências}

ALEIXO, Isabela. "O que a autobiografia de Angela Davis nos ensina sobre racismo epistêmico no Brasil". Geledés - Instituto da Mulher Negra. 24/04/2019. Disponível em: https://www.geledes.org.br/ o-que-a-autobiografia-de-angela-davis-nos-ensina-sobre-racismo-epistemico-no-brasil/. Acesso em: 09/01/2020.

DAVIS, Angela. Uma autobiografia. Trad. de Hecci Regina Candiani. São Paulo: Boitempo, 2019.

MÍDIA NINJA. \#AoVivo Angela Davis em São Paulo. YouTube, 21/10/2019. Disponível em: https:// www.youtube.com/watch?v=xK9yHUaVRe4. Duração: 2h40'30'. Acesso em: 10/01/2020.

TV PUC-Rio. "A "Escrevivência" na Literatura Feminina de Conceição Evaristo". YouTube. 16/05/ 2017. Disponível em: https://www.youtube.com/watch?v=z8C5ONvDoU8. Duração: 14'59'. Acesso em: 08/01/2020.

Carolina Cechella Philippi (carolinacechella@gmail.com) é historiadora formada pela Universidade Federal de Santa Catarina e pedagoga pela Universidade do Estado de Santa Catarina. É doutora em Educação pela Universidade Estadual de Campinas, tendo defendido tese sob orientação do Professor Dr. André Paulilo. Seus principais temas de estudo são História da Educação, Burocracia e Políticas Educacionais.

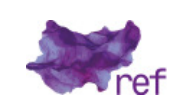




\section{COMO CITAR ESSE ARTIGO DE ACORDO COM AS NORMAS DA REVISTA}

PHILIPPI, Carolina Cechella. "Um movimento (auto)biografado". Revista Estudos Feministas, Florianópolis, v. 29, n. 1, e72141, 2021.

\section{CONTRIBUIÇÃO DE AUTORIA}

Não se aplica.

\section{FINANCIAMENTO}

Conselho Nacional de Desenvolvimento Científico e Tecnológico - CNPq.

\section{CONSENTIMENTO DE USO DE IMAGEM}

Não se aplica.

APROVAÇÃO DE COMITÊ DE ÉTICA EM PESQUISA

Não se aplica.

\section{CONFLITO DE INTERESSES}

Não se aplica.

\section{LICENÇA DE USO}

Este artigo está licenciado sob a Licença Creative Commons CC-BY International. Com essa licença você pode compartilhar, adaptar, criar para qualquer fim, desde que atribua a autoria da obra.

\section{HISTÓRICO}

Recebida em 12/03/2020

Aprovada em 11/04/2020 